\title{
Voz do cantor lírico e coordenação motora: uma intervenção baseada em Piret e Béziers
}

\author{
Lyric singer voice and motor coordination: \\ an intervention based on Piret and Béziers
}

\author{
Enio Lopes Mello', Marta Assumpção de Andrada e Silva² ${ }^{2}$ Leslie Piccolotto Ferreira ${ }^{3}$, Martha Herr ${ }^{4}$
}

\begin{abstract}
RESUMO
Objetivo: Investigar os efeitos da aplicação de um Programa de Desenvolvimento da Coordenação Motora, baseado em Piret e Béziers, na voz do cantor lírico. Métodos: Cinco cantores líricos profissionais executaram uma ária de ópera, de livre escolha, que foi filmada. Em seguida responderam a uma questão sobre a propriocepção ao cantar. Durante um mês submeteram-se ao Programa de Desenvolvimento da Coordenação Motora e ao final gravaram novamente a mesma ária e responderam a mesma questão. As filmagens foram enviadas para nove juizes profissionais (três fonoaudiólogos, três fisioterapeutas e três professores de canto) que avaliaram a integração corpo e voz dos cantores por meio de análise perceptivo-auditiva e visual. Os cantores, após assistirem às duas filmagens, fizeram outra auto-avaliação. Resultados: Na avaliação dos juízes: as duas sopranos, a mezzo-soprano e o baixo melhoraram a projeção da voz; o tenor melhorou a ressonância e o baixo melhorou também a respiração; com exceção do baixo todos ficaram com os gestos mais livres. Segundo relato dos cantores, os exercícios garantiram maior percepção da tensão muscular durante o canto e isso possibilitou melhor controle dos gestos. Conclusão: De acordo com a avaliação subjetiva os ajustes posturais, oriundos da execução dos exercícios da coordenação motora, provavelmente garantiram abertura da caixa torácica e melhoraram as condições da respiração dos cantores, durante o canto; este fato pode ter favorecido a verticalização da ressonância e a projeção da voz.
\end{abstract}

Descritores: Voz; Movimento; Atividade motora; Desempenho psicomotor

\section{INTRODUÇÃO}

A expressão vocal dos cantores líricos necessita de adequação na coordenação pneumofonoarticulatória (CPFA), devido ao grau de exigência e refinamento para a elaboração do canto $^{(1)}$. Porém, pergunta-se: será que a CPFA acontece isolada de outras partes do corpo, ou existe correlação entre a

Trabalho realizado no Programa de Estudos Pós-graduados em Fonoaudiologia da Pontifícia Universidade Católica de São Paulo - PUC-SP - São Paulo (SP), Brasil.

(1) Mestre, cantor lírico, terapeuta corporal especializado em Cadeias Musculares e Articulares pelo Institut des Chaînes Musculaires et Techniques Godelieve Dennys-Struyf - GDS - Bruxelas, Bélgica.

(2) Doutora, Professora do Programa de Estudos Pós-graduados em Fonoaudiologia da Pontifícia Universidade Católica de São Paulo - PUC-SP - São Paulo (SP), Brasil; Professora adjunto do Curso de Graduação em Fonoaudiologia da Faculdade de Ciências Médicas da Santa Casa de São Paulo FCMSCSP - São Paulo (SP), Brasil.

(3) Doutora, Professora do Curso de Graduação em Fonoaudiologia e do Programa de Estudos Pós-graduados em Fonoaudiologia da Pontifícia Universidade Católica de São Paulo - PUC-SP - São Paulo (SP), Brasil.

(4) Livre-docente, cantora lírica, Professora da Universidade Estadual Paulista "Júlio de Mesquita Filho" - UNESP - São Paulo (SP), Brasil.

Endereço para correspondência: Enio Lopes Mello. R. Juréia, 394/161, Chácara Inglesa, São Paulo (SP), Brasil, CEP: 04140-110.

E-mail: enio.mello@ superig.com.br

Recebido em: 19/6/2008; Aceito em: 29/12/2008 coordenação dos acontecimentos motores, de modo geral, e a expressão vocal de cada cantor?

Há um comprometimento da movimentação corporal com ajustes vocais, que está baseado nos mecanismos reflexos, que ocorrem durante a vocalização ${ }^{(2-5)}$. Os movimentos da vocalização respondem aos movimentos corporais, por meio dos receptores mecânicos presentes na laringe ${ }^{(2)}$. Eles propiciam ajustes nas pregas vocais à menor oscilação do corpo. $\mathrm{O}$ controle desse mecanismo configura-se em uma habilidade passível de aprimoramento. Quando um estímulo de movimento corporal chega até o sistema nervoso periférico (SNP), pode oscilar a pressão glótica e subglótica, alterar a vibração das pregas e aumentar a frequência fundamental ${ }^{(3-4)}$.

Sabe-se que a coordenação da abertura da glote é iniciada pela contração dos músculos cricoaritenóideos posteriores (CAP). As inervações desses músculos fornecem uma atividade rítmica que se inicia antes da ação motora do centro frênico, que por sua vez, coordena o ritmo ${ }^{(6-7)}$. Esses acontecimentos respiratórios decorrem dos ajustes das tensões no tórax, segundo a demanda da atividade a que se propõe $\mathrm{e}^{(8-9)}$. No canto, observa-se que o loudness é caracterizado segundo a pressão subglótica, em decorrência do ritmo e do volume respiratório ${ }^{(10)}$.

Ajustes que acontecem na musculatura do tronco durante 
a inspiração para o canto comprometem a postura corporal e interferem na qualidade vocal. Na cobertura de voz, por exemplo, a potência do som, a emissão facilitada com estabilidade e o brilho na voz, são garantidos, se houver aumento da pressão diafragmática sobre os músculos abdominais, abertura das costelas por ação dos músculos intercostais, alinhamento da postura e de colocação do som na "máscara"(11).

Nessa perspectiva e na compreensão de que a voz cantada não é resultado de um único órgão, mas de um conjunto de estruturas que se coordenam, aplicou-se ao aprimoramento e à análise da voz, o raciocínio empregado para a compreensão da coordenação motora do corpo todo, segundo Piret e Béziers ${ }^{(12)}$.

O objetivo desta pesquisa foi investigar os efeitos da aplicação de um Programa de Desenvolvimento da Coordenação Motora (PDCM), baseado em Piret e Béziers, na voz do cantor lírico.

\section{Princípios da coordenação motora, segundo Piret e Béziers}

A coordenação motora ${ }^{(12)}$ é uma atividade do Sistema Nervoso Central (SNC), que regula o sincronismo da contração e do relaxamento muscular, para elaboração dos movimentos corporais, via Sistema Nervoso Periférico (SNP). Todavia, cada sujeito elabora o movimento a partir do próprio movimento. São os movimentos corporais que permitem estabelecer a propriocepção e com isso, criar uma condição de controle e elaboração dos mesmos para a organização segmentar do corpo todo. Essa organização mecânica do corpo é construída com base no princípio de elementos esféricos tensionados pelos músculos condutores.

Existem unidades de coordenação que descrevem um movimento de enrolamento, isto é, aproximação dos dois elementos rotatórios. Na unidade de coordenação do tronco, os dois elementos rotatórios, abóbada esfenoidiana e a abóbada pélvica giram em seus eixos para lados opostos, respectivamente para cima e para baixo e com isso aproximam a bacia e a cabeça.

Esses movimentos são potencializados pela tensão de flexão somatória de pequenos movimentos, ao longo das articulações vertebrais inter-apofisárias e isso caracteriza o sistema reto. Este sistema possui dois eixos, posterior e anterior, por onde se prolongam os músculos, que estabilizam as abóbadas da cabeça e da bacia, durante o movimento de enrolamento e endireitamento da coluna, denominado elipse tronco.

Além do sistema reto, existe o sistema cruzado, que define os movimentos de torção do tronco. Nesses movimentos ocorre uma organização do tronco implicada em gestos antagônicos entre a cabeça e a bacia; o tronco e os membros. Portanto, o sistema cruzado é a cadeia de músculos que conduz à torção da elipse tronco; o sentido das fibras musculares da camada profunda (enrolamento-flexão) forma um X com o sentido das fibras musculares da camada superficial (endireitamento-extensão), e isso tem implicação direta no posicionamento do diafragma.

As fibras laterais dos músculos abdominais (oblíquos internos e externos) se cruzam. O movimento do obliquo interno ocorre depois do movimento da camada profunda dos intercostais internos e médios. Isto se dá porque suas fibras têm a mesma direção. Elas inclinam as costelas, enquanto o tórax e a asa ilíaca se aproximam. Em contrapartida, a camada superficial (intercostais externos) abre o tórax e depois o oblíquo afasta o tórax das asas ilíacas.

No pescoço, os músculos intercostais profundos trabalham após os escalenos, eles flexionam a coluna cervical, enquanto os intercostais superficiais trabalham após os espinhais e o serrátil posterior superior que, juntos, abrem o tórax e endireitam a coluna cervical. Dessa forma, a camada cruzada profunda garante a flexão, enquanto a camada superficial mantém a extensão.

\section{MÉTODOS}

Esta pesquisa, de caráter descritivo, foi aprovada pelo Comitê de Ética do Programa de Estudos Pós-graduados em Fonoaudiologia da Pontifícia Universidade Católica de São Paulo (PUC-SP), nº 45/2005, contou com a participação voluntária de cinco cantores líricos profissionais da cidade de São Paulo: duas sopranos - S(a) e S(b); uma mezzo-soprano - MS; um tenor - T e um baixo - B.

Os critérios de inclusão foram: não apresentar alterações na voz (falada ou cantada) segundo avaliação perceptivo-auditiva realizada pelos pesquisadores e não apresentar problemas de saúde e/ou comprometimento das vias aéreas superiores e inferiores nos dias das gravações.

\section{Procedimentos}

\section{Gravações}

Cada cantor interpretou uma ária de ópera de livre escolha, ensaiada e memorizada, duas vezes: uma antes de iniciar o PDCM (primeira gravação) e outra ao final do mesmo (segunda gravação). Recomendou-se aos cantores que fizessem aquecimento vocal antes das gravações. Os registros foram realizados por uma videomaker profissional, que utilizou uma câmera filmadora digital (PD-150-Sony) parada sobre tripé a três metros do cantor, para tomadas do corpo inteiro.

Para melhor visualização dos movimentos corporais, durante as gravações, os cantores usaram bermuda preta e camiseta regata bege palha, que foram oferecidas pelos pesquisadores.

\section{Questionamento sobre propriocepção}

Imediatamente, após as gravações (primeira e segunda), cada cantor respondeu por escrito: qual é a percepção que você tem de si mesmo, ao executar essa ária de ópera?

\section{$P D C M$}

Os exercícios desse programa resultaram da prática profissional do primeiro pesquisador, durante sete anos, junto a cantores líricos na Escola de Reeducação do Movimento Ivaldo Bertazzo (ERMIB), na qual já fora professor. Na elaboração dos exercícios respeitou-se os princípios descritos por Piret e Béziers $^{(12)}$, principalmente no que tange a reestruturação do sistema reto e do sistema cruzado (Anexo 1).

O programa foi realizado em grupo, teve carga horária de doze horas (dois encontros semanais de uma hora e 30 minutos cada, durante quatro semanas). Os cantores praticaram os exercícios do PDCM com roupas apropriadas e com os pés descalços. 


\section{Relatório de aula}

Ao final de cada encontro o pesquisador elaborou um relatório, no qual registrou e avaliou o aproveitamento, as dificuldades, o envolvimento e a disponibilidade dos cantores para execução dos exercícios.

\section{Avaliação dos juízes}

As gravações foram editadas, de forma sequencial segundo sorteio aleatório, e enviadas para nove juízes: três fonoaudiólogas com experiência em atendimento a cantores; três terapeutas corporais formados no método de Piret e Béziers e três professores de canto lírico. Os juízes fizeram análise perceptivo-auditiva e visual das gravações, por meio de um protocolo (Anexo 2).

\section{Auto-avaliação}

Cada cantor, após assistir às suas duas gravações (primeira e segunda), responderam ao protocolo (Anexo 2).

\section{Análise dos dados}

As respostas ao questionamento sobre a propriocepção de cada cantor, pré e pós PDCM, foram avaliadas e comparadas aos relatórios de aula.
As avaliações das gravações, feitas pelos juízes, foram comparadas à auto-avaliação dos cantores.

\section{RESULTADOS}

No Quadro 1 apresentam-se as respostas sobre a propriocepção de cada cantor e a avaliação do pesquisador. Na coluna "Propriocepção pré" constam as análises das respostas de cada cantor sobre a propriocepção antes da intervenção; na "Propriocepção pós" as análises das respostas depois da intervenção; na coluna "Relatório de aula" constam as avaliações feitas pelo pesquisador sobre cada cantor.

Após várias leituras das respostas dos cantores e dos juízes, sobre a avaliação das gravações criaram-se categorias. Essas foram elaboradas a partir da repetição de termos que representam mudanças positivas na voz e no corpo dos cantores:

- Categorias da voz: melhor projeção; melhor ressonância; melhor coordenação; melhor respiração; mais brilho.

- Categorias do corpo: gestos mais livres; melhor coordenação; melhor respiração; mais expressivo.

- As categorias diferente e igual referem-se à primeira parte das perguntas do protocolo (Anexo 2).

A partir da elaboração das categorias analisou-se o percentual de repetição sobre a avaliação de cada cantor.

Quadro 1. Avaliação proprioceptiva pré e pós-intervenção e avaliação feita pelo pesquisador, segundo relatório de aula

\begin{tabular}{|c|c|c|c|}
\hline Sujeito & Propriocepção pré & Relatório de aula & Propriocepção pós \\
\hline $\mathrm{S}(\mathrm{a})$ & $\begin{array}{l}\text { - sinto tensões nas articulações; } \\
\text { - perco o foco da voz; } \\
\text { - meu ar está escasso; } \\
\text { - não mantenho apoio vocal; } \\
\text { - não consigo manter frases longas; } \\
\text { - não tenho controle da respiração. }\end{array}$ & $\begin{array}{l}\text { - questionadora; } \\
\text { - dificuldade de compreender } \\
\text { os exercícios; } \\
\text { - persistente; } \\
\text { - bem humorada; } \\
\text { - entregue a novas abordagens. }\end{array}$ & $\begin{array}{l}\text { - melhorei o desempenho do corpo; } \\
\text { - percebi melhora na voz; } \\
\text { - tenho mais apoio basal; } \\
\text { - fluxo de ar mais controlado e livre; } \\
\text { - faço menos esforço; } \\
\text { - minha ressonância mudou; } \\
\text { - melhorou minha auto-estima }\end{array}$ \\
\hline$S(b)$ & $\begin{array}{l}\text { - às vezes, canto sem me envolver com } \\
\text { o personagem; } \\
\text { - faço dissociação de mim com o } \\
\text { personagem; } \\
\text { - fico concentrada na respiração; } \\
\text { - corpo cansado ao finalizar uma peça. }\end{array}$ & $\begin{array}{l}\text { - dificuldade para prestar atenção; } \\
\text { - muito dispersa; } \\
\text { - sempre de bom humor } \\
\text { - mostrou-se mais interessada nas } \\
\text { questões respiratórias; } \\
\text { - medo de movimentar o ombro direito } \\
\text { (rompimento de ligamento). }\end{array}$ & $\begin{array}{l}\text { - maior expansão da costela; } \\
\text { - percepção corporal interferiu na minha } \\
\text { voz; } \\
\text { - observo que a disposição física } \\
\text { melhorou; } \\
\text { - mais percepção do diafragma; } \\
\text { - facilidade para cantar. }\end{array}$ \\
\hline MS & $\begin{array}{l}\text { - tensão e sobrecarrega na região da } \\
\text { cervical; } \\
\text { - esforço respiratório; } \\
\text { - respiração é mais abdominal; } \\
\text {-ressonância comprimida } \\
\text { - meu corpo não "comporta" o meu } \\
\text { "corpo de voz". }\end{array}$ & $\begin{array}{l}\text { - muito aplicada; } \\
\text { - apresentou desconforto respiratório } \\
\text { nas aulas } \\
\text { - aproveitamento satisfatório para a } \\
\text { preparação corporal; } \\
\text { - relaxamento da tensão excessiva; } \\
\text { - muito questionadora. }\end{array}$ & $\begin{array}{l}\text { - integração plena entre meu corpo e } \\
\text { minha voz; } \\
\text { - percebi que o desconforto respiratório } \\
\text { estava associado a falta de percepção; } \\
\text { - estou atenta às coisas, que antes } \\
\text { me pareciam irrelevante, como por } \\
\text { exemplo: tensão excessiva no joelho e } \\
\text { na cervical. }\end{array}$ \\
\hline $\mathrm{T}$ & $\begin{array}{l}\text { - preocupação com a técnica; } \\
\text { - tensão na região do pescoço; } \\
\text { - ansiedade e medo de errar; } \\
\text { - movimentação desvia a tensão. }\end{array}$ & $\begin{array}{l}\text { - muito nervoso; } \\
\text { - questionador; } \\
\text { - dificuldade em se entregar aos } \\
\text { comandos; } \\
\text { - pouca percepção corporal; } \\
\text { - persistente. }\end{array}$ & $\begin{array}{l}\text { - aprendi distribuir a tensão; } \\
\text { - coluna alinhada ajuda o ar; } \\
\text { - postura ajudou o canto, nesse aspecto } \\
\text { estou melhor; } \\
\text { - minha percepção esta melhor; } \\
\text { - deposito mais empenho técnico. }\end{array}$ \\
\hline B & $\begin{array}{l}\text { - sair de si, anular a si mesma para } \\
\text { interpretar o personagem; } \\
\text { - a percepção da emoção e do cantar } \\
\text { às vezes é bloqueadora e isso traz } \\
\text { preocupação. }\end{array}$ & $\begin{array}{l}\text { - muito dedicado e disciplinado; } \\
\text { - percebeu-se varias vezes provocando } \\
\text { tensão desnecessária no corpo e na } \\
\text { voz; } \\
\text { - observou que mesmo em exercícios } \\
\text { de brincadeira coloca muito peso na } \\
\text { voz. }\end{array}$ & $\begin{array}{l}\text { - a consciência mais desperta; } \\
\text { - mais consciência corporal; } \\
\text { - corpo mais firme e menos rígido; } \\
\text { - percebi mudanças na voz, esta mais } \\
\text { sonora, menos metalizada, e mais solta } \\
\text { - coordenei um pouco de tudo. }\end{array}$ \\
\hline
\end{tabular}

Legenda: $\mathrm{S}(\mathrm{a})=$ soprano $\mathrm{a} ; \mathrm{S}(\mathrm{b})=$ soprano $\mathrm{b} ; \mathrm{MS}=$ mezzo-soprano; $\mathrm{T}=$ tenor; $\mathrm{B}=$ baixo 
Tabela 1. Resultados da avaliação das gravações por categorias da voz

\begin{tabular}{|c|c|c|c|c|c|c|c|c|c|c|}
\hline \multirow{3}{*}{ Categorias da voz } & \multicolumn{10}{|c|}{ Sujeitos } \\
\hline & \multicolumn{2}{|c|}{$S(a)$} & \multicolumn{2}{|c|}{$S(b)$} & \multicolumn{2}{|c|}{ MS } & \multicolumn{2}{|c|}{$\mathrm{T}$} & \multicolumn{2}{|c|}{ B } \\
\hline & $\mathrm{N}$ & $\%$ & $\mathrm{~N}$ & $\%$ & $\mathrm{~N}$ & $\%$ & $\mathrm{~N}$ & $\%$ & $\mathrm{~N}$ & $\%$ \\
\hline Diferente & 8 & 80 & 8 & 80 & 10 & 100 & 10 & 100 & 10 & 100 \\
\hline Igual & 2 & 20 & 2 & 20 & 0 & 0 & 0 & 0 & 0 & 0 \\
\hline Melhor projeção & 9 & 90 & 9 & 90 & 10 & 100 & 8 & 80 & 10 & 100 \\
\hline Melhor ressonância & 2 & 20 & 4 & 40 & 8 & 80 & 10 & 100 & 6 & 60 \\
\hline Mais brilho & 0 & 0 & 4 & 40 & 6 & 60 & 2 & 20 & 4 & 40 \\
\hline Melhor coordenação & 0 & 0 & 5 & 50 & 4 & 40 & 2 & 20 & 2 & 20 \\
\hline Melhor respiração & 0 & 0 & 6 & 60 & 3 & 30 & 10 & 100 & 3 & 30 \\
\hline
\end{tabular}

Distribuição numérica e percentual: $\mathrm{N}=10$ (9 juizes + cantor)

Legenda: $\mathrm{S}(\mathrm{a})=$ soprano $\mathrm{a} ; \mathrm{S}(\mathrm{b})=$ soprano $\mathrm{b} ; \mathrm{MS}=$ mezzo-soprano; $\mathrm{T}=$ tenor $\mathrm{B}=$ baixo

Tabela 2. Resultados da avaliação das gravações por categorias do corpo

\begin{tabular}{|c|c|c|c|c|c|c|c|c|c|c|}
\hline \multirow{3}{*}{ Categorias do corpo } & \multicolumn{10}{|c|}{ Sujeitos } \\
\hline & \multicolumn{2}{|c|}{$S(a)$} & \multicolumn{2}{|c|}{$S(b)$} & \multicolumn{2}{|c|}{ MS } & \multicolumn{2}{|c|}{$\mathrm{T}$} & \multicolumn{2}{|c|}{ B } \\
\hline & $\mathrm{N}$ & $\%$ & $\mathrm{~N}$ & $\%$ & $\mathrm{~N}$ & $\%$ & $\mathrm{~N}$ & $\%$ & $\mathrm{~N}$ & $\%$ \\
\hline Diferente & 10 & 100 & 10 & 100 & 10 & 100 & 10 & 100 & 10 & 100 \\
\hline Igual & 0 & 0 & 0 & 0 & 0 & 0 & 0 & 0 & 0 & 0 \\
\hline Gestos mais livres & 10 & 100 & 10 & 100 & 10 & 100 & 10 & 100 & 2 & 20 \\
\hline Melhor coordenação & 3 & 30 & 6 & 60 & 7 & 70 & 4 & 40 & 7 & 70 \\
\hline Melhor respiração & 2 & 20 & 0 & 0 & 2 & 20 & 4 & 40 & 10 & 100 \\
\hline Mais expressivo & 2 & 20 & 8 & 80 & 9 & 90 & 5 & 50 & 2 & 20 \\
\hline
\end{tabular}

Distribuição numérica e percentual: $\mathrm{N}=10$ (9 juizes + cantor)

Legenda: $\mathrm{S}(\mathrm{a})=$ soprano $\mathrm{a} ; \mathrm{S}(\mathrm{b})=$ soprano $\mathrm{b} ; \mathrm{MS}=$ mezzo-soprano; $\mathrm{T}=$ tenor $\mathrm{B}=$ baixo

Na Tabela 1 apresentam-se os resultados das avaliações das gravações feitas pelos juízes e a auto-avaliação de cada cantor na categoria voz.

Na Tabela 2 apresentam-se os resultados das avaliações das gravações feitas pelos juízes e a auto-avaliação de cada cantor na categoria corpo.

\section{DISCUSSÃO}

Os exercícios do PDCM foram elaborados com o propósito de ativar a coordenação motora de cada participante. Para isso, as dinâmicas de concentração proprioceptiva, de ritmos e de forças foram bastante variadas ${ }^{(12-13)}$. Essas variações tiveram como meta retirar o cantor de uma postura cômoda, conhecida, possivelmente fixa ${ }^{(13)}$, e conduzi-lo a uma condição de novas sensações, para ampliar os movimentos corporais e vocais. Com isso, estabelecer uma dialética com o conhecimento intelectual que, quando transposto para a vivência corporal, responde a uma consciência mais elaborada, na qual as possibilidades de movimentos se diferenciam e se refinam ao longo do desenvolvimento ${ }^{(2,12)}$.

Esses aspectos são integralmente subjetivos e os resultados relativos; isso causou certa limitação e dificuldade na análise e na compreensão dos dados, visto que cada cantor executou os exercícios segundo um padrão próprio de endendimento e coordenação motora. Diante disso, foram necessárias as avaliações de todos os cantores sobre si mesmos, dos juízes e dos pesquisadores, para se chegar a um resultado comum. Isso conferiu um aspecto qualitativo à análise dos dados.

Embora haja uma distinção na formação dos juízes dessa pesquisa, observou-se nas avaliações que, de modo geral, houve consenso na linguagem e nos conceitos. Isto se deve à aproximação das áreas correlacionadas, Canto, Fonoaudiologia, Educação Física e Fisioterapia. Esse fato facilitou a criação das categorias e, consequentemente, a compilação dos resultados.

De maneira geral, os cinco cantores executaram todos os exercícios propostos, sem restrições e sem que houvesse obrigatoriedade. Essa é uma condição de respeito aos limites físicos, psíquicos e vocais de cada cantor, em que se priorizou a subjetividade na compreensão e execução dos exercícios de modo estimulante. Isto é, cada cantor, com tempo e ritmo próprios, executou todos os exercícios, sob a orientação do primeiro pesquisador, porém cada qual com um padrão psicomotor singular ${ }^{(1-2,12-13)}$.

A cantora S(a), após a segunda gravação, descreveu um quadro de muita ansiedade e nervosismo que tivera durante a noite, por questões pessoais. Ela relatou que não conseguiu dormir, que fumou muito e teve muito refluxo gastresofágico, isso provocou muita secreção na voz ${ }^{(14-16)}$. Chegou muito agitada para a segunda gravação, temia não conseguir gravar. Nota-se nas filmagens, que a qualidade da voz dessa cantora 
não teve mudanças significativas, porém ela própria percebeu mudanças positivas em vários aspectos, tais como: proprioceptivos, ressonância, expressividade. Ressalta-se, que o fumo não foi um critério de exclusão, visto que todos os cantores, independente dos hábitos e vícios podem se beneficiar com os exercícios do PDCM.

$\mathrm{Na}$ segunda gravação, a cantora apresentou-se com maior abertura da caixa torácica e com melhor apoio dos pés no chão. Isso melhorou a respiração, quando comparada com a primeira gravação. Esse fato teve implicação direta no apoio $\operatorname{vocal}^{(7)}$. As tensões musculares não impediram que os movimentos corporais ficassem livres, a postura ficou mais adequada durante o canto e isso facilitou a projeção da voz ${ }^{(5-}$ 6). Nos relatos proprioceptivos (Quadro 1) a cantora discorreu sobre os benefícios que o PDCM lhe proporcionou: melhor postura, fluxo de ar mais livre, novos pontos de ressonância, menos esforço ao cantar, resgate da auto-estima.

A projeção da voz de $\mathrm{S}(\mathrm{b})$ apresentou um resultado expressivo, porém não foi unanimidade entre os juízes. As mudanças corporais merecem destaque nas categorias gestos mais livres e melhor expressividade. Na auto-avaliação ela confirma a opinião dos juízes, ao dizer que estava mais tranquila, que sentiu a voz com mais vibração.

Em alguns momentos, na primeira gravação, houve agitação dos movimentos na tentativa de tomada de ar. Possivelmente isso se deve a uma incoordenação pneumofonoarticulatória ${ }^{(1-3,13)}$. Nota-se também a voz mais tensa ${ }^{(1)}$ e com menos brilho, quando comparada com a segunda gravação.

Embora o corpo de $\mathrm{S}(\mathrm{b})$ apresente mudanças na segunda gravação, nota-se nas duas gravações que ela não conseguiu atingir um alinhamento da postura ${ }^{(17)}$. $\mathrm{O}$ ombro direito esteve mais baixo que o esquerdo. Isso se deve a uma lesão nos ligamentos ocasionado por um acidente ocorrido há dez anos. Segundo os conceitos da coordenação motora ${ }^{(12-13)}$, a estabilidade do sistema reto está prejudicada em virtude da lesão. Esse dado pode dar um aspecto negativo para quem assiste à gravação, porém para a cantora houve uma melhora significativa; ela relatou: "você sabe que depois dessas aulas eu esqueci que tenho um rompimento de fibra...". A despeito disso, observa-se que ela conseguiu manter abertura na caixa torácica na segunda gravação, o que, provavelmente, facilitou a respiração ${ }^{(7-11)}$. Consequentemente a voz está mais bem projetada e mais fluida ${ }^{(1)}$. Em suma, não obstante ao fato da postura desalinhada, o que se observa, é que a respiração e os movimentos corporais livres possibilitaram uma melhor projeção da voz e a expressão mais tranquila. Isso pode ser interpretado como uma adaptação do sistema cruzado, pois embora a postura não estivesse ajustada, os membros superiores e inferiores estavam livres para expressão $0^{(12-13)}$.

Quanto à cantora MS, embora sua respiração não tenha sido observada por todos, a melhora da projeção da voz foi unanimidade. Esse parâmetro está intimamente relacionado à capacidade respiratória e à postura corporal, principalmente do tronco ${ }^{(8-10,13)}$. No quesito corpo, os juízes avaliaram que os gestos ficaram mais livres, e esse dado pode ser interpretado, como uma habilidade adquirida, proveniente de boa propriocepção e coordenação dos gestos ${ }^{(2-4,12-13)}$. Logo, a projeção da voz melhorou em função dos ajustes posturais e dos gestos mais livres, que certamente facilitaram a respiração ${ }^{(12-13)}$. Esses dados foram confirmados pela cantora na auto-avaliação, por meio de um relato que remete às reflexões sobre a personalidade e às escolhas de cada sujeito. Ela disse: "minha voz mudou, porém não está suave, mas eu não sou suave, como vou querer que a voz seja; minha voz tem que ser carregada mesmo". As escolhas dos cantores podem auxiliar na investigação de novas possibilidades de produção vocal. No caso dessa cantora, a escolha do padrão de produção da voz exprime a sua personalidade ${ }^{(12-13,15)}$.

Nas duas gravações MS manteve-se com um bom padrão de articulação das palavras ${ }^{(1)}$. Porém, na primeira filmagem aparece uma mancha vermelha no colo (em cima do manúbrio), que talvez esteja relacionada ao excesso de força e pressão respiratória durante a execução da ária, fato que caracteriza uma incoordenação pneumofonoarticulatória ${ }^{(1-3,6,8-9,13,18)}$. Na segunda gravação esse avermelhado não ocorreu. Possivelmente a cantora conseguiu equalizar a força respiratória ao movimento vocal e consequentemente a voz ficou mais bem projetada. Esse resultado parece comprovar que os gestos livres ( sistema cruzado) possibilitaram melhora na coordenação dos movimentos corporais e da respiração $0^{(1,13)}$.

$\mathrm{O}$ cantor $\mathrm{T}$, na primeira gravação, executou a ária com movimentos de braços exagerados, ressonância laringofaríngea e com foco nasal acentuado. Na segunda gravação, os movimentos dos braços foram minimizados, ficaram mais suaves e delicados, fato que conferiu mais harmonia entre a voz e o $\operatorname{corpo}^{(1,13)}$.

Nos relatos proprioceptivos (Quadro 1) o cantor mencionou que a percepção e a posição da coluna ficaram melhores, fato que facilitou os ajustes da técnica vocal. Isso possivelmente contribuiu para a melhora na voz observada na segunda gravação: a ressonância mais agradável na região laringofaríngea com foco nasal discreto. Compreende-se esse fato pela análise dos ajustes corporais (tanto na postura, quanto nos movimentos); o cantor preocupou-se em manter os pés bem apoiados e o tronco um pouco antevertido ${ }^{(12-13)}$. Essa condição, provavelmente, favoreceu o desbloqueio da caixa torácica e, consequentemente, facilitou a passagem do $\operatorname{ar}^{(1-5)}$.

Na segunda gravação, T chegou muito agitado e cansado de uma viagem, ao entrar na sala mostrou-se com medo de não alcançar as notas agudas da ária. A sustentação das notas agudas exige muita disposição física e quando se está cansado o temor é justificado ${ }^{(1,10,13,19-20)}$. Porém, para surpresa do cantor, as notas aconteceram, até mais suaves e com uma cobertura de voz diferente, mais agradável, quando comparada com a primeira gravação ${ }^{(1,11,13)}$. Nota-se nesse resultado que, embora o cantor não estivesse de posse do controle das motivações psíquicas (teve medo), a resposta psicomotora foi acionada. $\mathrm{Ou}$ seja, os exercícios do PDCM garantiram um suporte de base para as condições motoras se desenvolverem e criarem autonomia. Isto é, o corpo estava preparado suficientemente para que as notas pudessem ser emitidas de modo coordenado ${ }^{(1,3,10,12-13)}$.

Para o cantor B as motivações psíquicas permitiram as realizações das motivações psicomotora e motora e esses dados foram contemplados nas respostas da propriocepção ${ }^{(13,15)}$, ou seja, consciência mais desperta, percebeu voz mais sonora, conquistou mais firmeza e menos rigidez (Quadro 1). 
Contrariamente às orientações dadas nos encontros, na segunda gravação B se apresentou imóvel. Porém, ele fez o seguinte comentário: "as ventosas nos pés e a extensão axial da coluna me ajudaram a interpretar o personagem. Trata-se de um sacerdote muito sério, que olha os súditos/fiéis de cima para baixo, enquanto canta. Então eu fiz a mesma coisa".

Na segunda gravação, a voz desse cantor está mais afinada devido à boa tomada de ar, a abertura da caixa torácica está maior, quando comparada com a primeira gravação ${ }^{(1-4,13)}$. Embora o cantor tenha minimizado seus movimentos corporais, a postura corporal está mais organizada, melhorou a estruturação do sistema cruzado, e com isso, o corpo está mais harmônico com a voz ${ }^{(1,13)}$; nota-se também mais apoio vocal devido o suporte respiratório ${ }^{(8,21-22)}$.

Segundo os princípios da coordenação motora ${ }^{(12)}$ os movimentos (gestos) dependem da motivação psíquica ${ }^{(12,15)}$, da criação mental do gesto, da realização e da satisfação da motivação. Todos esses aspectos marcam a subjetividade ${ }^{(14)} \mathrm{e}$ caracterizam a atitude; portanto não houve comparação entre os cantores.

As atitudes dos cantores foram compreendidas no plano subjetivo e no plano objetivo. No plano subjetivo implica em certa emoção, ou certo sentimento, que traduz o modo como o sujeito vive e se relaciona com outras pessoas. No plano objetivo, revela-se por meio de reações corporais ou verbais. Com base nessa noção de atitude tem-se a compreensão da organização estrutural do ser, via unidade do corpo funcional e do psiquismo ${ }^{(12-13,23)}$.

Ao analisar a criação mental do gesto, que é da ordem psicomotora, vê-se o desejo e sua realização implicados em um processo que passa por um estágio de representação da imagem corporal ${ }^{(12-13,15)}$. Essa representação pode ser compreendida como a maneira que o cantor se percebe ao cantar, isto é, sua propriocepção.

Para compreender o gesto de cantar, na sua totalidade, não é necessário conhecer cada uma dessas motivações a fundo, porém é essencial compreender as interferências que existem entre elas ${ }^{(24)}$; isso pode garantir uma noção corporal global.

De início, o desejo se torna necessário e toma uma forma realizável por meio da criação mental do ato de cantar ${ }^{(23)}$. Essa criação se situa no nível do esquema corporal, na memória e na imaginação, que permitem ao cantor conceber o ato ${ }^{(15)}$.

A representação do gesto executado está intimamente ligada ao esquema corporal, isto é, à imagem do corpo no mo- mento da ação e à emoção que se interpreta ${ }^{(15,23-24)}$. Sabe-se que quando o estímulo obtém uma resposta satisfatória, por meio da organização proprioceptiva, basta que seja bem realizado uma vez, para que o indivíduo seja capaz de reproduzi-lo e elaborá-lo. Se o mesmo for executado com periodicidade e regularidade certamente mais benefício trará para a realização correta do gesto ${ }^{(19)}$.

Os resultados oriundos da aplicação do PDCM, de modo geral, corresponderam aos objetivos propostos para a realização desta pesquisa. As bases teóricas da coordenação motora ${ }^{(12)}$ aplicadas na elaboração dos exercícios de reestruturação e manutenção da postura dos cantores ${ }^{(13)}$ contemplaram o sistema reto. A reestruturação dos gestos também foi contemplada com os exercícios do sistema cruzado que garantiram liberação das tensões corporais excessivas. Os trabalhos de associação entre os dois sistemas (reto e cruzado) preservaram os volumes internos, principalmente o volume do tórax, e auxiliaram na expressão vocal e corporal. Esses benefícios associados à propriocepção dos cantores viabilizaram o aprimoramento dos recursos vocais, com destaque para a projeção da voz e as mudanças na ressonância.

\section{CONCLUSÃO}

O canto lírico é uma ação que deve ser coordenada, pois a musculatura intrínseca da laringe está atrelada à coordenação pneumofonoarticulatória, que está associada à coordenação motora do corpo todo. A partir desse pressuposto a aplicação do Programa de Desenvolvimento da Coordenação Motora, junto aos cantores líricos profissionais dessa pesquisa, possivelmente possibilitou:

- maior percepção e controle das tensões musculares;

- diminuição das tensões musculares e liberação dos gestos, melhorando a respiração e a qualidade vocal;

- maior abertura da caixa torácica e, consequentemente, melhor condição de respiração; fato que favoreceu a verticalização da ressonância e a projeção da voz.

\section{AGRADECIMENTOS}

À Coordenação de Aperfeiçoamento de Pessoal de Nível Superior (CAPES) pelo apoio financeiro concedido (2006/2007). 


\begin{abstract}
Purpose: To investigate the effects of the application of a Motor Coordination Development Program, based on Piret and Béziers, on the voice of lyric singers. Methods: Five professional lyric singers performed an opera aria of their choice, which was filmed. Next, they answered a question regarding their proprioception when singing. They were submitted to the Motor Coordination Development Program for a month, after which each subject performed the same aria and answered the same question. The videos were sent to nine professional judges (three speech therapists, three physical therapists and three singing teachers), who carried auditory-perceptive and visual analyses of the singers' body and voice integration. After watching the two recordings, the subjects carried out another self-evaluation. Results: In the judges' evaluation: the two sopranos, the mezzo-soprano and the bass improved their voice projection; the tenor improved the resonance, and the bass also improved the breathing; all subjects, except the bass, showed freer gestures after the program. According to the singers' report, the exercises guaranteed greater perception of the muscular tension when singing, and that allowed more control of gestures. Conclusion: According to the subjective analysis, the postural adjustments deriving from the execution of motor coordination exercises probable guaranteed greater opening of the thoracic cavity and improved the breathing conditions of the subjects while singing, which might have favored the verticalization of resonance and the projection of the voice.
\end{abstract}

Keywords: Voice; Movement; Motor activity; Psychomotor performance

\title{
REFERÊNCIAS
}

1. Andrada e Silva MA, Duprat AC. Voz Cantada. In: Ferreira LP, BefiLopes DM, Limongi SCO, organizadores. Tratado de fonoaudiologia. São Paulo: Editora Rocca; 2004. p. 178-94.

2. Davis PJ, Bartlett Jr D, Luschei ES. Coordination of the respiratory and laryngeal system in breathing and vocalization: response. In: Titze IR, editor. Vocal fold physiology: frontiers in basic science. San Diego, Calif.: Singular Pub. Group; c1993. p. 189-226.

3. Miller R. The mechanics of singing: coordinating physiology and acoustics in singin. In: Benninger MS, Jacobson BH, Johnson AF. Vocal arts medicine: the care and prevention of professional voice disorders. New York: Thieme; 1994. p. 61-71.

4. Miller R. The coordination vocal onset and release. In: Miller R. The struture of singing: system and art in vocal technique. New York: Schirmer Books; 1996. p. 1-19.

5. Pettersen V, Bjorkoy K, Torp H, Westgaard RH. Neck and shoulder muscle activity and thorax movement in singing and speaking tasks with variation in vocal loudness and pitch. J Voice. 2005;19(4):623-34.

6. Thomasson M, Sundberg J. Consistency of phonatory breathing patterns in professional operatic singers. J Voice. 1999;13(4):529-41.

7. Hirano M. Vocal mechanisms in singing: laryngological and phoniatric aspects. J Voice. 1988;2(1):51-69.

8. Thorpe CW, Cala SJ, Chapman J, Davis PJ. Patterns of breath support in projection of the singing voice. J Voice. 2001;15(1):86-104.

9. Iwarsson J. Effects of inhalatory abdominal wall movement on vertical laryngeal position during phonation. J Voice. 2001;15(3):384-94.

10. Schutte HK, Stark JA, Miller DG. Change in singing voice production, objectively measured. J Voice. 2003;17(4):495-501.

11. Pacheco COLC, Marçal M, Pinho SMR. Registro e cobertura: arte e ciência no canto. Rev CEFAC. 2004;6(4):429-35.

12. Piret S, Béziers MM. A coordenação motora: aspecto mecânico da organização psicomotora do homem. São Paulo: Summus; 1992.

13. Mello EL. Voz do cantor lírico: efeitos da aplicação de um programa de desenvolvimento da coordenação motora baseado em Piret e Béziers [dissertação]. São Paulo: Pontifica Universidade Católica de São Paulo; 2008 .
14. Pereira PFA, Penteado RZ. Desenhos e depoimentos: recursos para investigação da percepção e do conhecimento vocal. Rev CEFAC. 2007;9(3):383-96.

15. Silva RF, Venditti Júnior R, Miller J. Imagem corporal na perspectiva de Paul Schilder: contribuições para trabalhos corporais nas áreas de educação física, dança e pedagogia. Rev Digital - Buenos Aires [Internet]. 2004;10(68):cerca de 6p. [citado 2009 Jul 12] Disponível em: http://www.efdeportes.com/efd68/schilder.htm

16. Cammarota G, Masala G, Cianci R, Palli D, Capaccio P, Schindler A, et al. Reflux symptoms in professional opera choristers. Gastroenterology. 2007;132(3):890-8. Erratum in: Gastroenterology. 2007;133(4):1393. Comment in: Curr Gastroenterol Rep. 2007;9(4):25960. Gastroenterology. 2008;134(7):2192-3; author reply 2193-4.

17. Rubin JS, Mathieson L, Blake E. Posture and voice. J Singing. 2004;60:271-5.

18. Amir O, Amir N, Michaeli O. Evaluating the influence of warmup on singing voice quality using acoustic measures. J Voice. 2005;19(2):25260.

19. Silva BARS, Martinez FG, Pacheco AM, Pacheco I. Efeitos da fadiga muscular induzida por exercícios no tempo de reação muscular dos fibulares em indivíduos sadios. Rev Bras Med Esporte. 2006;12(2):85-9.

20. Solomon NP. Vocal fatigue and its relation to vocal hyperfunction. Int J Speech Lang Pathol. 2008;10(4):254-66.

21. Aydos B, Hanayama EM. Técnicas de aquecimento vocal utilizadas por professores de teatro. Rev CEFAC. 2004;6(1):83-8.

22. Rubin JS, Blake E, Mathieson L. Musculoskeletal patterns in patients with voice disorders. J Voice. 2007;21(4):477-84.

23. Czermak R. Do significado ao ato: sentido e criação na análise. Estud Psicanal. 2005;(28):117-21.

24. Muszkat M, Correia CMF, Campos SM. Música e neurociências. Rev Neurociências. 2000;8(2):70-5. 
Anexo 1. Programa de Desenvolvimento da Coordenação Motora (PDCM)

\begin{tabular}{|c|c|c|c|c|}
\hline Encontros & $1^{\circ}$ & $2^{\circ}$ & $3^{\circ}$ & $4^{\circ}$ \\
\hline Temas & $\begin{array}{l}\text { Percepção e } \\
\text { reconhecimento dos } \\
\text { movimentos da bacia e MI }\end{array}$ & $\begin{array}{l}\text { Percepção e } \\
\text { reconhecimento dos } \\
\text { movimentos do tronco e MS }\end{array}$ & $\begin{array}{l}\text { Movimentos e } \\
\text { posicionamento da cabeça e } \\
\text { pescoço }\end{array}$ & Postura em pé equilibrada \\
\hline Objetivos & $\begin{array}{l}\text { Fazer avaliação da } \\
\text { postura e do gesto; } \\
\text { estimular a percepção, o } \\
\text { posicionamento, e controle } \\
\text { dos movimentos da bacia e } \\
\text { dos MI }\end{array}$ & $\begin{array}{l}\text { Flexibilizar o tronco em } \\
\text { enrolamento e extensão; } \\
\text { preservar volumes internos } \\
\text { e movimentos livres de } \\
\text { MS; garantir abertura } \\
\text { dos espaços intercostais; } \\
\text { promover a extensão axial } \\
\text { da coluna vertebral }\end{array}$ & $\begin{array}{l}\text { Trabalhar os músculos } \\
\text { extensores, flexores e } \\
\text { rotadores da cabeça; } \\
\text { os músculos faciais } \\
\text { para garantir controle e } \\
\text { expressividade }\end{array}$ & $\begin{array}{l}\text { Reconhecer e perceber as } \\
\text { estruturas anatômicas e } \\
\text { os movimentos corporais; } \\
\text { garantir condições para } \\
\text { a homeostase física; } \\
\text { restabelecer a coordenação } \\
\text { motora }\end{array}$ \\
\hline Exercicio 1 & $\begin{array}{l}\text { Sentar em uma banqueta } \\
\text { com apenas um ísquio, pés } \\
\text { apoiados no chão, mãos nas } \\
\text { coxas. Fazer movimentos } \\
\text { de subir e descer o quadril } \\
\text { (ilíaco) que está livre (5X) }\end{array}$ & $\begin{array}{l}\text { DL: posição de germe } \\
\text { (aproximar joelhos e } \\
\text { cabeça): fazer movimento de } \\
\text { desenrolar da coluna ( } 2 X) \text {, } \\
\text { iniciar a força pelo reto- } \\
\text { abdominal. }\end{array}$ & $\begin{array}{l}\text { Escovar os músculos da } \\
\text { face na direção das fibras: } \\
\text { zigomático, masseter, } \\
\text { orbicular da boca e dos } \\
\text { olhos, frontal, temporal, asas } \\
\text { do nariz, digástrico. }\end{array}$ & $\begin{array}{l}\text { Escovação do corpo em } \\
\text { dupla: DV: apoiar uma } \\
\text { almofada na barriga. O } \\
\text { colega escova de cima para } \\
\text { baixo, desde o trapézio } \\
\text { (nuca) até o tornozelo. }(6 \mathrm{X})\end{array}$ \\
\hline Exercício 2 & $\begin{array}{l}\text { DL: apoiar a cabeça numa } \\
\text { almofada, flexionar as } \\
\text { pernas. Fazer movimentos } \\
\text { para aproximar e distanciar } \\
\text { o ilíaco das costelas }(5 X)\end{array}$ & $\begin{array}{l}\text { QA: um colega apóia a } \\
\text { mão esquerda no sacro } \\
\text { e a direita na nuca, fazer } \\
\text { movimento com as costas, } \\
\text { para cima e para baixo, com } \\
\text { contra-resistência }\end{array}$ & $\begin{array}{l}\text { Escovar os músculos do } \\
\text { pescoço, trapézio, escaleno } \\
\text { e ESCOM de cima para } \\
\text { baixo. Fazer pequenos } \\
\text { movimentos de sim, não e } \\
\text { talvez com a cabeça }\end{array}$ & $\begin{array}{l}\text { Escovação do corpo em } \\
\text { dupla: DD: colega escova } \\
\text { de baixo para cima, inicia- } \\
\text { se nos pés até completar } \\
\text { ombros e braço ( } 6 \mathrm{X})\end{array}$ \\
\hline Exercício 3 & $\begin{array}{l}\text { DD: apoiar a cabeça em } \\
\text { uma almofada, apoiar os } \\
\text { polegares na parte superior } \\
\text { do púbis, fazer movimentos } \\
\text { de báscula anterior e } \\
\text { posterior da bacia }(5 X)\end{array}$ & $\begin{array}{l}\text { DD: perna direita esticada e } \\
\text { cruzada sobre a esquerda, } \\
\text { braço direito alongado acima } \\
\text { da cabeça rente ao chão, } \\
\text { permanecer }\end{array}$ & $\begin{array}{l}\text { Exercício da cabeça para } \\
\text { frente contra-resistido: } \\
\text { colocar as mãos na testa e } \\
\text { inclinar cabeça para frente, } \\
\text { fazer contra-resistência, } \\
\text { permanecer ( } 10 \mathrm{~s})\end{array}$ & $\begin{array}{l}\text { EP: fazer ventosa na sola } \\
\text { dos pés, ensaiar varias } \\
\text { preensões no chão ( } 30 \mathrm{~s} \text { ) }\end{array}$ \\
\hline Exercício 4 & $\begin{array}{l}\text { EP: com os pés bem } \\
\text { apoiados no chão e } \\
\text { separados }(10 \mathrm{~cm}) \text {, } \\
\text { depositar o peso do corpo, } \\
\text { sobre os arcos-transversos } \\
\text { dos pés, imprimir rotação } \\
\text { externa nas coxas e rotação } \\
\text { interna nas tíbias, fazer } \\
\text { vibração (tremer) no corpo } \\
\text { todo }\end{array}$ & $\begin{array}{l}\text { EP: tronco flexionado } \\
\text { para frente (priorizar a } \\
\text { flexão da articulação coxa/ } \\
\text { fêmur), tocar o chão com } \\
\text { as mãos, agachar, fazer } \\
\text { movimento contrário a partir } \\
\text { da extensão das pernas, do } \\
\text { tronco e da cabeça }\end{array}$ & $\begin{array}{l}\text { Exercício da cabeça para } \\
\text { lateral direta contra-resistido: } \\
\text { apoiar a mão direita no } \\
\text { temporal direito e inclinar a } \\
\text { cabeça para o mesmo lado, } \\
\text { fazer contra-resistência } \\
\text { permanecer ( } 15 \text { s). Repetir } \\
\text { para o lado esquerdo }\end{array}$ & $\begin{array}{l}\text { EP: pés paralelos, plantas } \\
\text { dos pés bem apoiadas no } \\
\text { chão, peso do corpo sobre } \\
\text { os metatarsos, tíbias com } \\
\text { rotação interna, joelhos em } \\
\text { leve flexão, coxofemorais } \\
\text { com rotação externa, } \\
\text { extensão axial da coluna, } \\
\text { ombros abaixados, braços } \\
\text { paralelos ao tronco, com } \\
\text { flexão de cotovelos de } \\
\text { aproximadamente } 135^{\circ}, \\
\text { mãos em posição de } \\
\text { abóbadas, com dorsoflexão } \\
\text { dos punhos, cabeça } \\
\text { centralizada, olhar no } \\
\text { horizonte, } 30 \mathrm{~s}\end{array}$ \\
\hline Exercício 5 & $\begin{array}{l}\text { Exercício do tango. Em pé, } \\
\text { com apenas o pé direito } \\
\text { apoiado no chão, fazer } \\
\text { movimento de rotação } \\
\text { externa e interna com coxa } \\
\text { da perna esquerda }\end{array}$ & $\begin{array}{l}\text { Exercício do maestro: EP: } \\
\text { fazer movimentos elípticos } \\
\text { com os braços (descrever } \\
\text { o numero oito no ar), } \\
\text { primeiramente movimentos } \\
\text { na horizontal (oitos deitados) } \\
\text { e depois movimentos na } \\
\text { vertical (oitos em pé) }\end{array}$ & $\begin{array}{l}\text { Exercício da cabeça para } \\
\text { trás contra-resistido: apoiar } \\
\text { as mãos entrelaçadas na } \\
\text { nuca, inclinar de cabeça } \\
\text { para trás, fazer contra- } \\
\text { resistência, permanecer } \\
\text { (15 s) }\end{array}$ & \\
\hline Exercício 6 & & & $\begin{array}{l}\text { Exercícios rítmicos: dança } \\
\text { sem música, em compasso } \\
\text { ternário, marcar forte no } \\
\text { terceiro tempo (10X) }\end{array}$ & \\
\hline
\end{tabular}




\begin{tabular}{|c|c|c|c|c|}
\hline Encontros & $5^{\circ}$ & $6^{\circ}$ & $7^{\circ}$ & $8^{\circ}$ \\
\hline Temas & $\begin{array}{l}\text { Desenvolvimento } \\
\text { coordenado I }\end{array}$ & $\begin{array}{l}\text { Desenvolvimento } \\
\text { coordenado II }\end{array}$ & $\begin{array}{l}\text { Desenvolvimento } \\
\text { coordenado III }\end{array}$ & $\begin{array}{l}\text { Movimentos livres e } \\
\text { sincronizados com canto }\end{array}$ \\
\hline Objetivos & $\begin{array}{l}\text { Reconhecer e perceber } \\
\text { membros/articulações, } \\
\text { movimentos corporais; } \\
\text { enrolamento e } \\
\text { endireitamento do } \\
\text { tronco, associados à } \\
\text { sonorização }\end{array}$ & $\begin{array}{l}\text { Garantir abertura nas } \\
\text { articulações dos membros } \\
\text { superios e movimentos } \\
\text { livres; praticar a integração } \\
\text { coordenada entre o sistema } \\
\text { reto e o sistema cruzado }\end{array}$ & $\begin{array}{l}\text { Praticar a integração } \\
\text { coordenada entre o sistema } \\
\text { reto e o sistema cruzado; } \\
\text { testar reflexos para o } \\
\text { controle dos gestos }\end{array}$ & $\begin{array}{l}\text { Dinamizar corpo e voz, para } \\
\text { a elaborar o gesto, manter o } \\
\text { foco da voz; realizar atividade } \\
\text { proprioceptiva, sincronizar } \\
\text { gestos corporais e vocais; cantar } \\
\text { de modo coordnado dentro da } \\
\text { coreografia. }\end{array}$ \\
\hline Exercicio 1 & $\begin{array}{l}\text { De olhos vendados } \\
\text { fazer a sequência: } \\
\text { DV, agachar, levantar, } \\
\text { sentar na banqueta, } \\
\text { levantar, agachar e } \\
\text { deitar novamente. } \\
\text { Vocalizar em bocca } \\
\text { chiusa (6X) }\end{array}$ & $\begin{array}{l}\text { Sentar sobre as pernas } \\
\text { flexionadas, inclinar o tronco } \\
\text { para frente, apoiar a testa } \\
\text { no chão: um colega com as } \\
\text { mãos na boca, em forma de } \\
\text { funil, emitir sons graves e } \\
\text { agudos sobre os ossos do } \\
\text { sacro, escápulas e cervical, } \\
\text { (3X) em cada região }\end{array}$ & $\begin{array}{l}\text { * Ajoelhar sobre uma } \\
\text { pequena almofada, apoiar } \\
\text { o pé direito à frente, inclinar } \\
\text { o tronco para frente, manter } \\
\text { a extensão da coluna, tocar } \\
\text { as mãos no chão, sem tirar } \\
\text { a planta do pé direito, em } \\
\text { seguida voltar o tronco, em } \\
\text { posição ereta e inclinar para } \\
\text { trás (30 s) }\end{array}$ & $\begin{array}{l}\text { Cantar o exercício "Tal tatu" } \\
\text { (Anexo 3) e desenvolver a } \\
\text { coreografia de passar a bola: } \\
\text { em pé em fileira de três, um } \\
\text { de costas para o outro, cantar } \\
\text { e passar a bola (bola de } \\
\text { fisioterapia grande) no ritmo } \\
\text { da musica; variar a dinâmica: } \\
\text { ora lenta, ora rápida e lenta } \\
\text { novamente. (repetir o mesmo } \\
\text { exercício com bolas pequenas e } \\
\text { pesadas) }\end{array}$ \\
\hline Exercício 2 & $\begin{array}{l}\text { QA: fazer a sequência: } \\
\text { apoiar o pé direito no } \\
\text { chão, simultaneamente } \\
\text { elevar a mão direita } \\
\text { e descrever um arco; } \\
\text { parar o braço alongado } \\
\text { na frente do rosto, } \\
\text { alternar os lados direito } \\
\text { e esquerdo e associar } \\
\text { a vocalização /O/, (6X) }\end{array}$ & $\begin{array}{l}\text { *Sentar numa banqueta, } \\
\text { apoiar os pés no chão, } \\
\text { cruzar a perna direita sobre } \\
\text { a perna esquerda, fazer } \\
\text { rotação externa da coxa } \\
\text { direta com a ajuda das } \\
\text { mãos. Permanecer ( } 30 \text { s). } \\
\text { Levantar e sentar (6X) } \\
\text { manter a rotação externa } \\
\text { nas coxas e arredondar os } \\
\text { braços }\end{array}$ & $\begin{array}{l}\text { DD: flexionar a perna direita } \\
\text { sobre o tronco, flexionar } \\
\text { o braço esquerdo sobre } \\
\text { o peito, esticar perna } \\
\text { esquerda para o teto, esticar } \\
\text { braço direito para o teto, } \\
\text { fazer movimentos de flexão } \\
\text { e extensão, alternado entre } \\
\text { pernas e braços (10X) }\end{array}$ & $\begin{array}{l}\text { * Movimento do tango: em pé, } \\
\text { pé esquerdo apoiado no chão, } \\
\text { descrever o número oito com a } \\
\text { perna direita }(4 X)\end{array}$ \\
\hline Exercício 3 & $\begin{array}{l}\text { EP: flexionar o tronco } \\
\text { para frente, tocar } \\
\text { as mãos no chão, } \\
\text { simultaneamente } \\
\text { vocalizar /O/, começar } \\
\text { pianíssimo até } \\
\text { fortíssimo }(6 \mathrm{X})\end{array}$ & $\begin{array}{l}\text { * Segurar o músculo } \\
\text { pequeno peitoral (embaixo } \\
\text { da axila esquerda) com a } \\
\text { mão direita. Elevar o ombro } \\
\text { esquerdo, aproximar cabeça } \\
\text { do ombro. Fazer mobilização } \\
\text { do músculo para frente e } \\
\text { para trás e em seguida, } \\
\text { puxar para baixo (5X) }\end{array}$ & $\begin{array}{l}\text { Sentar sobre uma bola de } \\
\text { fisioterapia grande: agachar } \\
\text { até deslizar a bola nas } \\
\text { costas, sem usar as mãos, } \\
\text { simultaneamente vocalizar } \\
\text { /O/ prolongado (10X) }\end{array}$ & $\begin{array}{l}\text { Vocalizar em bocca chiusa a } \\
\text { música "Va pensiero" - Coro dos } \\
\text { escravos Hebreus da Ópera } \\
\text { Nabuco de G. Verdi (1842), } \\
\text { simultaneamente fazer o gesto } \\
\text { de embalar um bebê, abaixar e } \\
\text { levantar, manter a abertura das } \\
\text { costelas, fazer enrolamento da } \\
\text { coluna, alinhar e desalinhar todo } \\
\text { o corpo (2X) }\end{array}$ \\
\hline Exercício 4 & $\begin{array}{l}\text { DD: braços paralelos } \\
\text { ao corpo, pernas } \\
\text { flexionadas, pés } \\
\text { apoiados no chão. } \\
\text { Alongar as pernas } \\
\text { em direção ao teto, } \\
\text { não deixar os joelhos } \\
\text { em recurvatum, tudo } \\
\text { associado ao vocalize } \\
\text { (30s) }\end{array}$ & $\begin{array}{l}\text { * Sentar numa baqueta, } \\
\text { segurar o úmero direito } \\
\text { com a mão esquerda: puxar } \\
\text { para baixo e fazer rotação } \\
\text { interna. Simultaneamente } \\
\text { flexionar o cotovelo e punho } \\
(5 X)\end{array}$ & $\begin{array}{l}\text { Sentar sobre uma bola de } \\
\text { fisioterapia grande: pular } \\
\text { sentado e parar rapidamente } \\
\text { após cinco pulos, manter } \\
\text { a posição suspensa como } \\
\text { se fosse sentar novamente } \\
(10 X)\end{array}$ & $\begin{array}{l}\text { Cantar "Azulão" de Jaime Ovale } \\
\text { (1960): apoiar a barriga na bola } \\
\text { grande de fisioterapia, fazer } \\
\text { movimentos com os braços } \\
\text { para cima e para baixo (simular } \\
\text { batidas de asas) ao ritmo da } \\
\text { música, apoiar e levantar as } \\
\text { pernas do chão (simular calda de } \\
\text { um pássaro) (30 s) }\end{array}$ \\
\hline Exercício 5 & $\begin{array}{l}\text { Exercícios rítmicos: } \\
\text { dançar num compasso } \\
\text { ternário, acentuar o } \\
\text { terceiro tempo, associar } \\
\text { movimentos dos braços } \\
\text { ora simultâneo à perna, } \\
\text { que está à frente, ora } \\
\text { alternado, tudo com a } \\
\text { execução do vocalize } \\
\text { /O/ (30s) }\end{array}$ & $\begin{array}{l}\text { * Exercício rítmico EP: } \\
\text { posicionar os pés paralelos } \\
\text { e seguir a sequência: } \\
\text { Passo para a direita, } \\
\text { passo ao centro, passo } \\
\text { para a esquerda, passo ao } \\
\text { centro, passo para frente, } \\
\text { passo ao centro, passo } \\
\text { para trás, passo ao centro, } \\
\text { (2x). Na terceira repetição } \\
\text { acrescentar um tapa na sola } \\
\text { dos pés }\end{array}$ & $\begin{array}{l}\text { EP: em dupla (um de costas } \\
\text { para o outro), passar a bola } \\
\text { grande de fisioterapia para o } \\
\text { colega, por cima, pelo lado } \\
\text { esquerdo e pelo lado direito, } \\
\text { simultaneamente vocalizar } \\
\text { /O/ em qualquer tonalidade } \\
\text { (10X) em seguida cada um } \\
\text { com uma bola grande de } \\
\text { fisioterapia, passar a bola } \\
\text { para o colega do lado direito } \\
\text { (pingar a bola uma vez no } \\
\text { chão) }\end{array}$ & $\begin{array}{l}\text { Cantar a música "Suíte dos } \\
\text { pescadores" de Dorival Caymmi } \\
\text { (1965) e realizar a coreografia } \\
\text { do jogar a rede (lençol): Agachar } \\
\text { para pegar o lençol, levantar } \\
\text { protegendo a coluna, joelhos } \\
\text { sem recurvatum, braços com } \\
\text { flexão de cotovelos ângulo de } \\
135^{\circ} \text {. Em grupo manter o lençol } \\
\text { esticado, cada cantor segura } \\
\text { numa das pontas do lençol, } \\
\text { simular os movimentos do } \\
\text { diafragma na execução de uma } \\
\text { música, ou seja, na inspiração } \\
\text { abaixar e na expiração elevar o } \\
\text { lençol }\end{array}$ \\
\hline
\end{tabular}

Legenda: $\mathrm{MI}=$ membros inferiores; $\mathrm{MS}=$ membros superiores; $\mathrm{ESCOM}=$ esternoclidomastóideos; $\mathrm{DV}=$ decúbito ventral; $\mathrm{DL}=$ decúbito lateral; $\mathrm{DD}$ = decúbito dorsal; $\mathrm{QA}$ = quatro apoios; $\mathrm{EP}=$ em pé; * = fazer do outro lado 
Anexo 2. Protocolo de avaliação das gravações

Após assistir as duas gravações de cada cantor responda:

1) A voz está igual ( ) ou diferente ( )? Justifique sua resposta.

2) O corpo está igual ( ) ou diferente ( ) ?

Em qual gravação o corpo está mais harmônico com a voz? Gravação branca ( ） ou Gravação preta ( ). Por quê?

Observação: As gravações receberam o nome de branca e preta para não induzir os juízes com a cronologia das mesmas.

Anexo 3. Exercício realizado no $8^{\circ}$ encontro do PDCM

\section{Tal Tatu}

(Plínio)

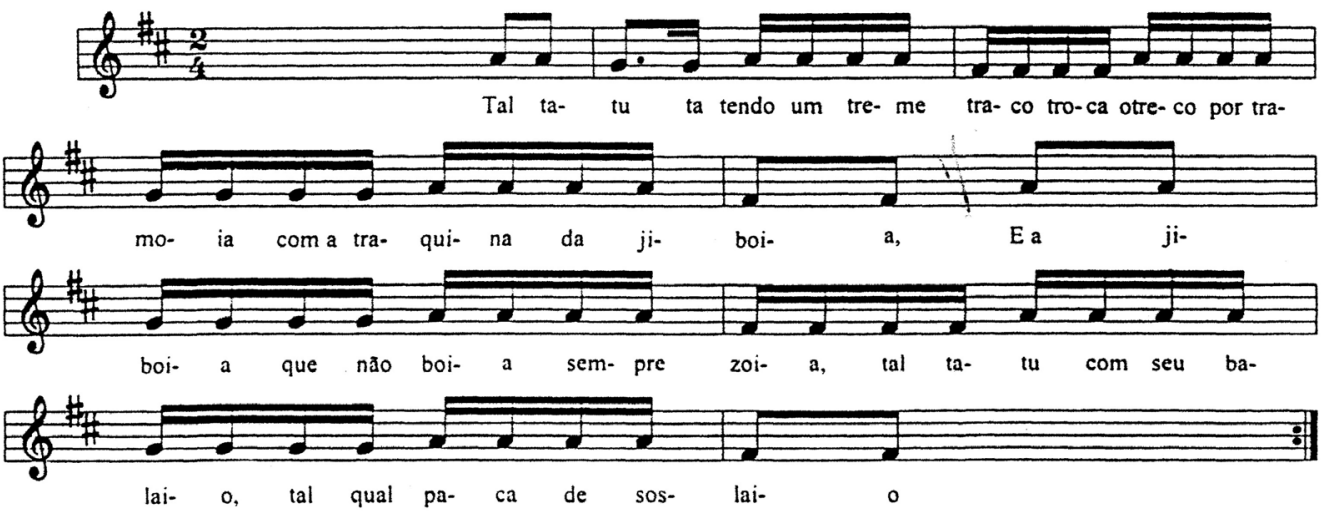

